\title{
EL ESTUDIO DE LA SEQUÍA DE PRINCIPIOS DEL SIGLO XIX EN ORIHUELA, A PARTIR DE LOS VALORES DE LAS ROGATIVAS «PRO PLUVIA»1
}

\author{
Ruth Zamora Pastor
}

\section{RESUMEN}

El estudio del clima histórico de Orihuela en el siglo XIX muestra la variabilidad temporal del mismo, puesto que a lo largo de dicha centuria se suceden varias fases secas, definidas gracias al análisis de la frecuencia con la que se realizaban las «rogativas pro pluvia». Una de estas fases es la que se desarrolló a principios del siglo, y que, aún siendo de intensidad moderada, sus efectos tuvieron importantes repercusiones en la economía de la zona.

Palabras clave: Sequía, «rogativa pro pluvia», frecuencia, niveles.

\section{ABSTRACT}

The study of the historic climate of Orihuela in the XIX century shows its temporal variability because some dry phases occurred along this period, defined by the analysis of the frequency of the celebration of «pro pluvia rogations». One of this phases was developed early last century and its effects on the economy of the region, were very serious, even though the dry period had a moderate intensity.

Key words: Drought, «pro pluvia rogations», frequency, level.

\section{Metodología y fuentes documentales para el estudio de las sequías históricas}

Para el estudio de las secuencias de indigencia pluviométrica ocurridas en tiempos históricos, es preciso recurrir a una metodología específica que permita, por un lado la obtención de información válida y, por otro, la cuantificación de los datos obtenidos.

1 Este trabajo forma parte de una tesina que lleva por título «Fluctuaciones climáticas en el Bajo Segura durante el siglo XIX». 
En primer lugar es preciso tener en cuenta que, para este tipo de estudios, es difícil disponer de observaciones directas de fenómenos meteorológicos, puesto que, en numerosas ocasiones las series instrumentales de los observatorios no comienzan hasta finales del siglo XIX, por lo que las fuentes documentales empleadas se reducen básicamente a dos, los archivos municipales y los eclesiásticos, a parte de la posibilidad de disponer de noticias en la prensa local.

Para el caso de las sequías, existe un tipo concreto de información que resulta de gran valor, se trata de los registros de «rogativas pro pluvia» que aparecen en los libros de Actas Capitulares de los diferentes archivos. La celebración de este tipo de ceremonia religiosa pone de manifiesto una notoria preocupación por parte de los organismos civiles y eclesiásticos, y, en definitiva, del pueblo, debido a la escasez de las precipitaciones, así como a la inminente necesidad de recursos hídricos. Esto se comprende mejor si se tiene en cuenta que la economía de la zona analizada se basaba en el cultivo de su rica huerta.

La celebración de la ceremonia de rogativa, seguía un esquema secuencial, estructurado en diferentes fases, que raramente era alterado, y que obedecía a una lógica basada en los convencionalismos y el funcionamiento burocrático de la época. Las fases que jalonan este proceso, de forma esquemática, serían las siguientes:

\begin{tabular}{|c|}
\hline $\begin{array}{c}\text { FENÓMENO CLIMÁTICO } \\
\text { (SEQUÍA) }\end{array}$ \\
\hline REPERCUSIONES EN PRODUCCIONES \\
AGRIICOLAS
\end{tabular}

En primer lugar se registra una merma considerable de las precipitaciones, sobre todo en las épocas del año en que éstas son más necesarias para las producciones agrícolas. Esto va a repercutir directamente en los cultivos, tanto los de secano como los de regadío, los primeros a causa de las exiguas lluvias, y los segundos por la reducción de los volúmenes de agua disponibles. Por todo ello, los labradores eran quienes primero advertían al Ayuntamiento del peligro de perder las cosechas a causa de la sequía. Este organismo público contaba entre sus funciones, la de comunicar al Cabildo Catedralicio las quejas recibidas, así como la necesidad de realizar «rogativas pro pluvia». Sin embargo, era este organismo eclesiástico el encargado de establecer la fecha de la celebración, si procedía llevarla a cabo.

Los datos que se obtienen a partir de la consulta de estos documentos, contienen una mayor riqueza, puesto que, no sólo resultan útiles a la hora de identificar los períodos de 
sequía a partir de la frecuencia con que se realizaron las ceremonias de rogativa, sino que, además, éstas permiten evaluar la gravedad de los mismos teniendo en cuenta las características de estas celebraciones religiosas. Los aspectos formales del culto eran tenidos muy en cuenta y se vigilaban con rigurosidad según el ritual romano, por lo tanto, cualquier modificación del rito induce a pensar que no era casual, sino que obedecía a unas pautas diferenciales, que eran aplicadas selectivamente en función de la situación que se vivía, es decir, según la gravedad de la sequía, se llevaba a cabo una u otra ceremonia. La mayor complejidad de la misma, implica, por tanto, una mayor intensidad del fenómeno climático. De este modo, para el caso de Orihuela, se han identificado hasta cuatro niveles de rogativas, que corresponden a diferentes grados de sequía.

\begin{tabular}{|l|l|l|}
\hline NIVEL & INTENSIDAD & TIPO DE CEREMONIA \\
\hline I & LEVE & Rogativas públicas \\
\hline II & MODERADA & Colecta «pro pluvia» en las misas \\
\hline III & GRAVE & $\begin{array}{l}\text { Exposición del intercesor (Santa María de } \\
\text { Monserrate o Jesús Nazareno) }\end{array}$ \\
\hline IV & MUY GRAVE & $\begin{array}{l}\text { Procesión del intercesor (Santa María de } \\
\text { Monserrate o Jesús Nazareno) }\end{array}$ \\
\hline
\end{tabular}

Al análisis combinado de ambas variables, frecuencia de celebración y niveles de las rogativas, es preciso añadir otra serie de datos que aparecen en las actas, que pueden resultar de gran interés a la hora de matizar la gravedad del fenómeno. Básicamente se trata de referencias al incremento del precio del trigo, gestación de epidemias, problemas relacionados con el derecho al uso de los recursos hídricos y con la salud pública, derivados estos últimos del estancamiento del caudal del río Segura, que atraviesa la ciudad de Orihuela.

De este modo, se logra llegar a identificar de forma clara los períodos más secos del siglo XIX, uno de los cuales, sin duda, fue el que caracterizó el inicio del siglo.

\section{La sequía de principios de siglo}

El inicio del siglo XIX, viene marcado por la escasez de precipitaciones, que se arrastra desde finales del XVIII. En efecto, durante el año de 1800 las cosechas fueron escasas debido a esta falta de agua, hasta el punto de llevar a los agricultores al borde de la ruina por no poder pagar los impuestos que les correspondía, por ello el Cabildo Eclesiástico decidió proceder a la celebración de una rogativa, que consistió en la lectura de la «colecta pro pluvia», tanto en la Catedral de Orihuela, como en el resto de iglesias, a partir del día 13 de marzo.

Sin embargo, a pesar de haber llovido adecuadamente, el viento de poniente hizo que la tierra se secara, empeorando la situación en la que se encontraban los agricultores y por ello solicitaron al Ayuntamiento que accediera exponer a pública veneración la imagen de Jesús Nazareno y así, pedir por lograr la lluvia.

En abril de ese mismo año, se detecta la falta de nieve en los pozos que la ciudad de Orihuela tiene para su abastecimiento en Sierra Espuña. Este hecho corrobora lo expresado 
por los labradores, pues no había nevado suficientemente donde sí era habitual que lo hiciera, lo cual es síntoma de una sensible disminución de las precipitaciones caídas.

Tras el verano, en el otoño de 1800, una epidemia de peste se declaró en la Península, pues, si bien la peste comenzó a ser excepcional en Europa desde mediados del siglo XVIII, esta epidemia continuó apareciendo de forma esporádica en algunas zonas del continente, aunque con menor virulencia que en los siglos anteriores. El agente causal de la peste es la Pasteurella pestis o bacilo de Yersin, y se gesta en las ratas, que se contagian entre sí directamente por canibalismo o por la picadura de las pulgas. La transmisión al hombre se produce, generalmente, a través de las pulgas. Las epidemias de peste se relacionan con las de hambre, que sin duda pueden ser debidas a crisis climáticas que determinan malas cosechas $\mathrm{y}$, por lo tanto, insuficiencia de alimentos. Por lo tanto, aunque de forma indirecta, la peste y el clima se relacionan, sin embargo, las condiciones desfavorables del clima causantes de las hambrunas, pueden ser de índole muy diversa y deberse tanto a la falta de agua como a su exceso, aunque es cierto que, en este caso concreto de la epidemia de principios del siglo XIX, es la escasez de precipitaciones la que ocasionó mermas importantes en las cosechas $\mathrm{y}$, por lo tanto, en los alimentos.

En efecto, en el acta del Ayuntamiento del 27 de octubre, se hace referencia a las actuales circunstancias del tiempo, ya por la peste que sufren otros Pueblos, ya por la falta de aguas sufrida por los labradores. Por ello se acordó que para implorar de la divina misericordia se hagan rogativas públicas el domingo 2 de noviembre, al tiempo se debía decir la "colecta pro pluvia", permaneciendo entretanto la imagen de Nuestra Señora Patrona de Monserrate en la Catedral. Por otra parte, si la situación no mejoraba, se sacaría en procesión la imagen de Santa María de Monserrate por las calles, llevándola por los tránsitos regulares y poniéndose en el día la Colecta. Esta cita resulta reveladora de una situación compleja, ya que, a parte de hallarse los organismos competentes ante condiciones meteorológicas adversas, éstos no descartan la posibilidad de su empeoramiento, pues si no llueve los problemas derivados de la sequía, se verían incrementados. Progresivamente, se convocan rogativas «pro pluvia» de niveles superiores, III y IV, lo cual es indicativo de un grado de sequía grave o muy grave.

Ya a principios del siglo XIX, en la primavera de 1801, continúan los problemas debido a que no había llovido de forma adecuada en el transcurso de los meses anteriores, y por tanto, las cosechas no se habían recuperado. Síntoma de ello es la referencia en las actas del ayuntamiento a que en años escasos como éste sube el precio del pan. En relación con ello, en el acta del día 8 de marzo, se recoge una queja de algunos labradores por la escasez de las cosechas, que no les permiten pagar lo que deben, ni sacar beneficios para sobrevivir. Por esta causa, solicitan que se hagan «rogativas pro pluvia» públicas, debido a la necesidad de lluvia, para las cosechas y para beber. Con este fin, se decidió exponer la sagrada imagen de Jesús Nazareno.

Con la sequía llegan los problemas relacionados con la sanidad, concretamente, el miedo de la población ante el posible desarrollo de epidemias se hace manifiesto. En el mes de abril se había detectado en Andalucía la presencia de «epidemias», por lo cual se hizo necesario tomar medidas de precaución, reduciendo a tres las puertas de acceso a la ciudad de Orihuela.

Tras la inundación de la huerta de Orihuela provocada por el desbordamiento del río Segura, el día 23 de diciembre de 1801, se detectó en esta ciudad un brote de paludismo o fiebres terciarias, cuyo origen se halla en el desarrollo del mosquito Anopheles, transmisor de esta enfermedad, y que para su gestación precisa de unas condiciones adecuadas de tem- 
peratura y humedad, que pudieron venir definidas por el estancamiento del agua tras la avenida, fenómeno que no es difícil de entender si se encuadra este incremento del nivel del agua del río, dentro de un marco de sequía y escasez de recursos hídricos, ya que una tierra sedienta rápidamente agotó este incremento puntual de las lluvias.

En ocasiones, durante épocas de escasez de precipitaciones, el Ayuntamiento adoptó medidas que poco o nada tienen que ver con cuestiones económicas, como el aumento del precio del trigo, o religiosas, como la celebración de rogativas «pro pluvia», en este caso, en el acta del día 16 de abril de 1801, el Ayuntamiento reconoce la grave situación por la que atraviesa la población a causa de la escasez de las cosechas y la miseria por la que atraviesan muchos agricultores, y para mejorar los ánimos se decidió contratar una compañía cómica.

Durante el verano de este año de 1801, la escasez de precipitaciones se manifestó en el insuficiente abastecimiento de nieve, de este modo, el 31 de agosto el Ayuntamiento advirtió una excesiva falta de nieve, habiéndose observado en otras ocasiones durante el corriente año, además de la mala calidad para desempeñar su función.

El año de 1802, marca un punto de inflexión dentro de la tónica dominante en esta década, es decir, la de sequías, a lo largo de este año, las condiciones de disponibilidad de recursos hídricos comenzaron a mejorar sensiblemente, hasta el punto de llegar a paliar la falta de agua que se venía registrando desde años atrás, sin embargo no fue suficiente para dar por concluida la sequía. En efecto, a principios de 1803, continúan los problemas, pues ya en febrero, el día 28, se acuerda por el ayuntamiento llevar a cabo «rogativas pro pluvia». El Cabildo Catedralicio concretó que se debía poner la Colecta para que se pida por el beneficio de la lluvia.

El precio del trigo, en ocasiones, es indicativo del estado de sequía, ya que un aumento del mismo implica escasez de granos, es decir, una mala cosecha que, sin duda, se puede relacionar con la escasez de agua. A lo largo de este año de 1803, se observan pequeñas fluctuaciones en el precio del trigo, a principios del verano se registró un descenso de 8 reales de vellón, ya que en primavera, el 2 de mayo, la fanega valía 68 y el 14 de junio 60, sin embargo, después volvió a subir a 63 reales la fanega el 4 de julio, y a 73 el 29 de agosto. Este incremento de su valor se ha de relacionar con la escasez de las cosechas que, a su vez, se vincula a la escasez de precipitaciones que se vivió a finales de la primavera y durante el verano, fenómeno que, por otro lado, se superpone al lamentable estado en que quedaron las tierras de cultivo tras la inundación que causó el desbordamiento del río Segura, debido a la rotura de la presa de Lorca, el primero de mayo de 1802. Como se puede observar, la realidad no obedece a esquemas de comportamiento simples, sino que es el resultado de la interacción de numerosos factores, que intervienen en la misma dirección, contribuyendo de este modo a amplificar el problema. En este caso, el efecto devastador de la riada dejó la huerta y campo de Orihuela en un estado de equilibrio inestable, así, esta predisposición a sufrir de manera más acusada la sequía, hizo que las pérdidas en las cosechas fueran de mayor entidad, además de las dificultades para rehacer los daños sufridos el año anterior causados por la avenida.

A finales de año, en acta del Ayuntamiento de 19 de diciembre, se expuso la necesidad de realizar nuevas rogativas, el Cabildo de la Catedral, recibió el recado dirigido al Deán el 22 de dicho mes, para que se dijese en la misa la Colecta «pro pluvia».

Durante ese mismo invierno, el día cinco de enero de 1804, continúa la preocupación por la progresiva escasez de precipitaciones que se venía registrando desde el año anterior. De este modo, habiendo recibido el Cabildo de la Catedral un recado del Ayuntamiento, en 
el que se notifica la necesidad de realizar una rogativa pública, con la intercesión de la Virgen de Monserrate, se decidió hacer las rogativas de la manera acostumbrada, empezando el Domingo por la mañana después de tercia las letanías mayores y lo mismo los días lunes y martes, a su vez, el Sacristán mayor dio aviso al Cavildo Provincial para que disponga que desde el día martes por la tarde y seguidamente los demás días, miércoles, jueves y siguientes, debían dirigirse en Rogativa a la Catedral las Parroquias de Santa Justa y Santiago y las comunidades religiosas que existían en la ciudad de Orihuela, para suplicar y pedir a su Divina Majestad que conceda el beneficio de la lluvia. Sin embargo, parece ser que la ceremonia no surtió el efecto deseado y, continuando la necesidad de agua, el Ayuntamiento, poco tiempo después, el día 25 de enero, recoge la queja de varios labradores que exponen la necesidad de agua que padecen los campos, con el consiguiente peligro de perder los sementeros. Solicitan que se celebren nuevas rogativas, sacando en procesión la imagen de Jesús Nazareno. Petición que este organismo decidió aceptar en la reunión celebrada el día 1 de febrero.

A lo largo del año de 1804, se pone de nuevo de manifiesto la importante escasez de granos y de otros productos de primera necesidad, que se padece en Orihuela, ya el 1 de febrero, el Ayuntamiento en sus actas recoge la necesidad de aumentar el precio del trigo, a 78 reales de vellón la fanega, así como la de subir también el precio del aceite. En la misma línea, el día 27 del mismo mes, se solicita por parte de los ciudadanos la subida de los salarios, ya que no pueden mantener a sus familias debido al aumento de precio de los alimentos y víveres. En marzo continúa subiendo el precio del trigo, a 82 reales de vellón la fanega. Durante el mes de agosto, el precio subió hasta llegar a comprarse a 97 reales de vellón la fanega. El día 3 de septiembre el Ayuntamiento declara la escasez de granos que se sufrió aquel año. En noviembre, el precio del trigo quedó en 108 reales de vellón la fanega, su máximo lo alcanzó en abril de 1805, llegando a los 113 reales de vellón la fanega, para luego ir regulándose a lo largo de este año.

A finales de 1804, la peste azotó la ciudad de Orihuela. Esta epidemia, que a principios del siglo se había detectado en otras zonas de la Península, ahora se extendió por esta comarca. Como ya se ha dicho, la epidemia se relaciona con la sequía, una población mal alimentada a causa de la carestía de productos de primera necesidad, es un excelente substrato para el desarrollo de la enfermedad, así como también lo es la escasez y pésima calidad del agua de que disponen. En el fondo, un fenómeno climático desencadena graves consecuencias que alcanzan la propia salud de la población, pues de un lado facilita el contagio y, de otro, dificulta la posible contención de la enfermedad.

De la lectura de las actas referentes a 1805, se deduce que el invierno y la primavera fueron secos, la subida que el precio del trigo sufrió en abril, así como la rogativa realizada en marzo, son muestra de ello. En efecto, el día 11 de marzo, los labradores piden al Ayuntamiento que se realice una rogativa al Todo Poderoso para que conceda lluvia para que crezcan los sementeros. Varios días más tarde, el Cabildo de la Catedral recoge en sus actas que ya había cesado el motivo por el cual se hacían Rogativas por el agua, pues había llovido suficientemente, sin embargo los daños en algunas cosechas no dejaron de notarse, pues en abril el trigo alcanzó el mayor precio registrado en años.

Continuando con la misma tónica de escasez de precipitaciones, los problemas derivados de la sequía ni siquiera se solucionaron con las fuertes lluvias que ocasionaron la inundación acontecida el 17 de noviembre de 1805. Estas lluvias contribuyeron a aliviar la situación, aunque de manera puntual, sin embargo, en enero de 1806, el día 22, algunos labradores remiten una petición al Ayuntamiento para que se lleve a cabo una rogativa para 
lograr que llueva, ya que los efectos de la falta de la misma se sufren en los sementeros. El Cabildo eclesiástico, reunido el 24 de dicho mes, aprobó la realización de Rogativas públicas con intercesión de Santa María de Monserrate. Sin embargo, en relación a la notoria falta de lluvia, se siguen sucediendo numerosas peticiones de los labradores para que se exponga a veneración pública la imagen de Jesús Nazareno, teniéndolo en cuenta, el Ayuntamiento acordó aprobar una rogativa de nivel III, que continuó tras el 26 de febrero.

Durante los meses siguientes, la situación se mantuvo, con lo cual la primavera de 1807, de nuevo fue problemática. Así, el día 1 de marzo, los labradores solicitan de nuevo la realización de «rogativas pro pluvia», el Ayuntamiento acordó que el día 5 se expusiera a pública veneración en la Catedral, la imagen de la Virgen de Monserrate, sin embargo, el Cabildo de la Catedral, ya había decidido el día 2 de marzo, ante la clara necesidad de agua en los campos, poner la colecta destinada a este particular. Al no producirse la tan deseada lluvia, la escasez continúa, y el 9 de marzo, el Cabildo eclesiástico recibe un recado de la ciudad para que se traiga la imagen de la Virgen de Monserrate a la Catedral, para que interceda con el Señor y conceda el beneficio de la lluvia, se fija la fecha de la traslación para el día 16, pero no se pudo llevar a cabo por haber llovido. Sin embargo estas lluvias no se consideraron suficientes para cubrir las necesidades, con lo cual se continuó con lo previsto. Finalmente llovió, en cantidad suficiente para poder servir a los cultivos, así, el día 1 de abril, se celebró en la Catedral una misa en acción de gracias a la Virgen de Monserrate por la lluvia caída.

Ese mismo otoño de 1807, el 19 de octubre, se encuentran nuevas referencias a la falta de agua a causa de la penuria en las precipitaciones registradas. El Ayuntamiento, teniéndolo presente, acordó comunicar al Cabildo de la Catedral la conveniencia de realizar una rogativa «pro pluvia» de nivel II, diciendo la oración «ad petendam pluviam» en la misa. Así lo concretó este organismo. Reunido el 22 de octubre, confirmó que desde el día 23 en adelante se dijese en la misa la colecta y que el síndico pasara al Obispo recado para que mandase decirla en las parroquias y comunidades de Orihuela. Al no producirse las deseadas lluvias, el 22 de diciembre el Ayuntamiento, teniendo en cuenta la necesidad de agua, de nuevo envió un aviso al Cabildo, para que se hiciesen nuevas rogativas, exponiendo a pública veneración en la Catedral la imagen de Santa María de Monserrate. Sin embargo, el Cabildo catedralicio manifestó que, a pesar de la necesidad de traer en rogativa la imagen de la Virgen de Monserrate para lograr el beneficio de la lluvia, no era posible proceder a ello, debido a las fechas en las que se efectúa la solicitud, es decir en Navidad, en las cuales el Cabildo no puede desatender sus obligaciones con sus feligreses, por ello decidió posponer la rogativa, en caso de que continuase la necesidad, para después de estas fechas. Sin embargo, la traslación de la sagrada imagen de Santa María de Monserrate no llegó a realizarse, parece ser que la situación mejoró con el inicio del año 1808, aunque en el acta del Ayuntamiento celebrada el día 29 de julio, el síndico Procurador General expuso los perjuicios y la lamentable situación de las cosechas del País, lo cual induce a pensar que, si bien la situación comenzaba progresivamente a estabilizarse, los daños ocasionados por la sequía, sobre todo en las cosechas, no dejaron de sentirse.

Durante los años siguientes, no se tiene noticia alguna acerca de la celebración de rogativas «pro pluvia», ni tampoco de otros elementos relacionados con la sequía. Este hecho, en parte se relaciona con la Guerra de la Independencia frente a las tropas napoleónicas, ya que el 28 de mayo de 1808 comenzó la guerra contra Francia en Alicante, y estas cuestiones centraron la mayor atención de los organismos públicos. Por otra parte, Alicante no fue conquistada por las tropas francesas y como ciudad libre debía realizar servicios especiales 
a las tropas, lo cual suponía una mayor carga económica para la población, la guerra implicaba un mayor consumo de trigo, y por extensión de todo tipo de alimentos. Teniendo en cuenta esta serie de factores, es lógico pensar en que la situación de los campos fue mejorando, gracias a la normalización de las condiciones de precipitación. En este sentido, un síntoma que apunta hacia el fin de la sequía, es la pequeña nevada que cayó a finales del año 1810 en Sierra Espuña.

Sin embargo, a pesar de la conclusión de la sequía, durante la década de los años diez, no dejaron de realizarse «rogativas pro pluvia», aunque con una frecuencia mucho menor que en la década anterior. Así, el 7 de marzo de 1811 se llevó a cabo una de nivel II, el 12 de enero de 1816 de nivel I, y en 1817, dos, una de nivel II el 6 de marzo, y otra de nivel III el 12 de marzo. Como se puede ver, en esta zona el «año sin verano», término con el que se denominó el año de 1816, no se manifestó del mismo modo que en otros lugares del planeta.

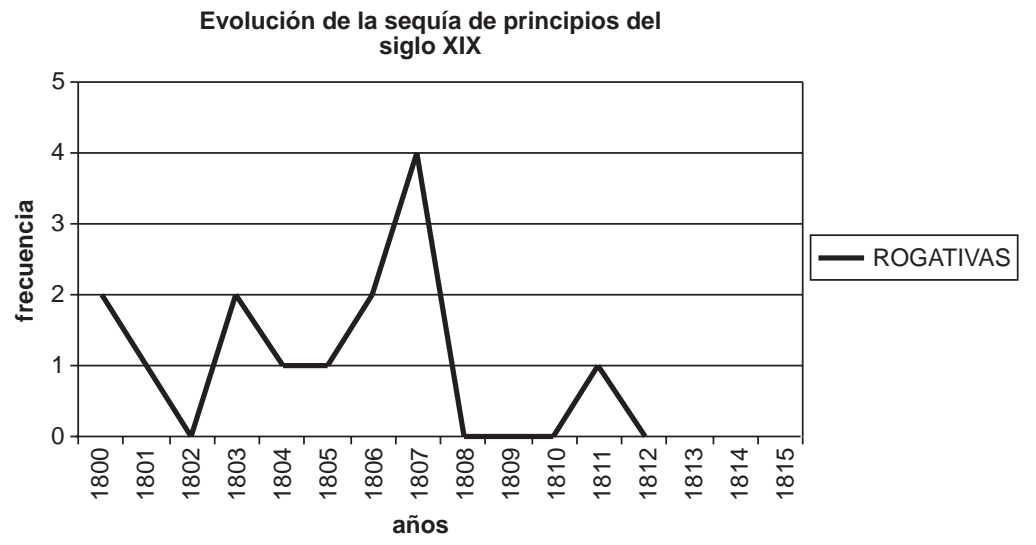

En el gráfico se observa claramente la evolución del período de sequía estudiado. La frecuencia con que se celebraron las ceremonias de rogativa, indica un empeoramiento de la situación hacia mediados del decenio analizado, llegando a realizarse hasta cuatro ceremonias de rogativa. Sin embargo, tras éste máximo, la tendencia es sensiblemente diferente, ya que desciende significativamente el número de ceremonias registradas, lo cual es significativo de una mejora de la situación con el inicio de la década de los años diez.

\section{Bibliografía}

Archivo Histórico Municipal de Orihuela: Libros de Actas Capitulares.

Archivo Histórico de la Catedral de Orihuela: Libros de Actas Capitulares.

BARBASTRO GIL, L. (1985): El clero valenciano en el Trienio Liberal (1820-1823). Alicante, Instituto de estudios Juan Gil-Albert.

CONEJERO MARTÍNEZ, V. (1985): La agricultura en la provincia de Alicante durante el siglo XIX. Alicante. Excma. Diputación Provincial de Alicante.

FONT TULlOT, I. (1988): Historia del Clima de España. Cambios climáticos y sus causas. Madrid, Instituto Nacional de Meteorología. 
GIL OLCINA, A. (1979): La propiedad señorial en tierras valencianas. Valencia. Artes gráficas Soler, S.A.

LE ROY LADURIE, E. (1990): Historia del clima desde el año mil. Mexico, D.F. Fondo de Cultura Económica S.A.

MARTÍN-VIDE, J. Y BARRIENDOS VALLVÉ, M. (1995): «The use of rogation ceremony records in climatic reconstruction: a case study from Catalonia (Spain)». Climatic Change, vol. XXX, pp. 201-221.

OLCINA CANTOS, J. (1994): Riesgos Climáticos en la Península Ibérica. Madrid. Acción Divulgativa S.L. 